G E U S

Report file no.

22217

GRøNLANDS GEOLOGISKE UNDERSØGELSE

Bulletin No. 65

\title{
THE PATTERN OF FOLDING
}

IN AN AREA OF MIGMATITES BETWEEN

NERIA AND QASIGIALIK FJORDS,

SOUTH-WEST GREENLAND

BY

FEIKO KALSBEEK

WITH 5 FIGURES IN THE TEXT AND 43 DIAGRAMS

Reprinted from

Meddelelser om Gronland, Bd. 175, Nr. 4

KØB EN HAVN

BIANCO LUNOS BOGTRYKKERI A/S 1967 
GRøNLANDS GEOLOGISKE UNDERSØGELSE BulletiN No. 65

\section{THE PATTERN OF FOLDING \\ IN AN AREA OF MIGMATITES BETWEEN NERIA AND QASIGIALIK FJORDS, SOUTH-WEST GREENLAND \\ BY}

FEIKO KALSBEEK

WITH 5 FIGURES IN THE TEXT AND 43 DIAGRAMS

Reprinted from

Meddelelser om Gronland, Bd.175, Nr. 4

KØB EN HAVN

BIANCO LUNOS BOGTRYKKERI A/S 


\begin{abstract}
A geometrical analysis of mesoscopic structures (foliation planes, lineations, minor fold axes) in an area of migmatites is presented. In spite of the intensive migmatization of the rocks the observations fit into a more or less regular pattern, which is interpreted as the result of three superimposed folding phases, the first of which was roughly contemporaneous with an important phase of metamorphism and the second with the migmatization of the rocks in the area. For the interpretation of great circle diagrams use has been made of a computer program to find a great circle of best fit, the pole of which is used as the most plausible fold axis in a number of subareas.
\end{abstract}




\section{CONTENTS}

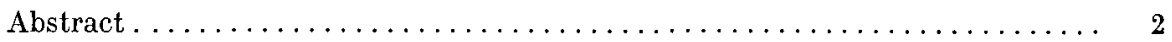

Introduction $\ldots \ldots \ldots \ldots \ldots \ldots \ldots \ldots \ldots \ldots \ldots \ldots \ldots \ldots \ldots \ldots \ldots$

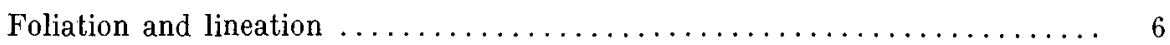

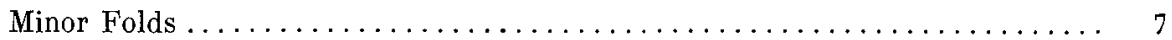

a) Isoclinal folds $\ldots \ldots \ldots \ldots \ldots \ldots \ldots \ldots \ldots \ldots \ldots \ldots \ldots \ldots$

b) Open folds $\ldots \ldots \ldots \ldots \ldots \ldots \ldots \ldots \ldots \ldots \ldots \ldots \ldots \ldots \ldots$

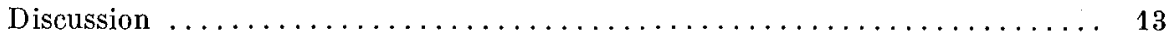

a) The age relationship between isoclinal and open folds ........... 13

b) The disposition of the constructed open fold axes $\ldots \ldots \ldots \ldots \ldots \ldots$

c) The effects of the large scale folding $\ldots \ldots \ldots \ldots \ldots \ldots \ldots \ldots \ldots \ldots$

d) The use of the calculation of 'best fitting' great circles. . . . . . . . . 16

Summary . . . . . . . . . . . . . . . . . . . . . . . . . . . 17

References $\ldots \ldots \ldots \ldots \ldots \ldots \ldots \ldots \ldots \ldots \ldots \ldots \ldots \ldots \ldots \ldots \ldots$ 


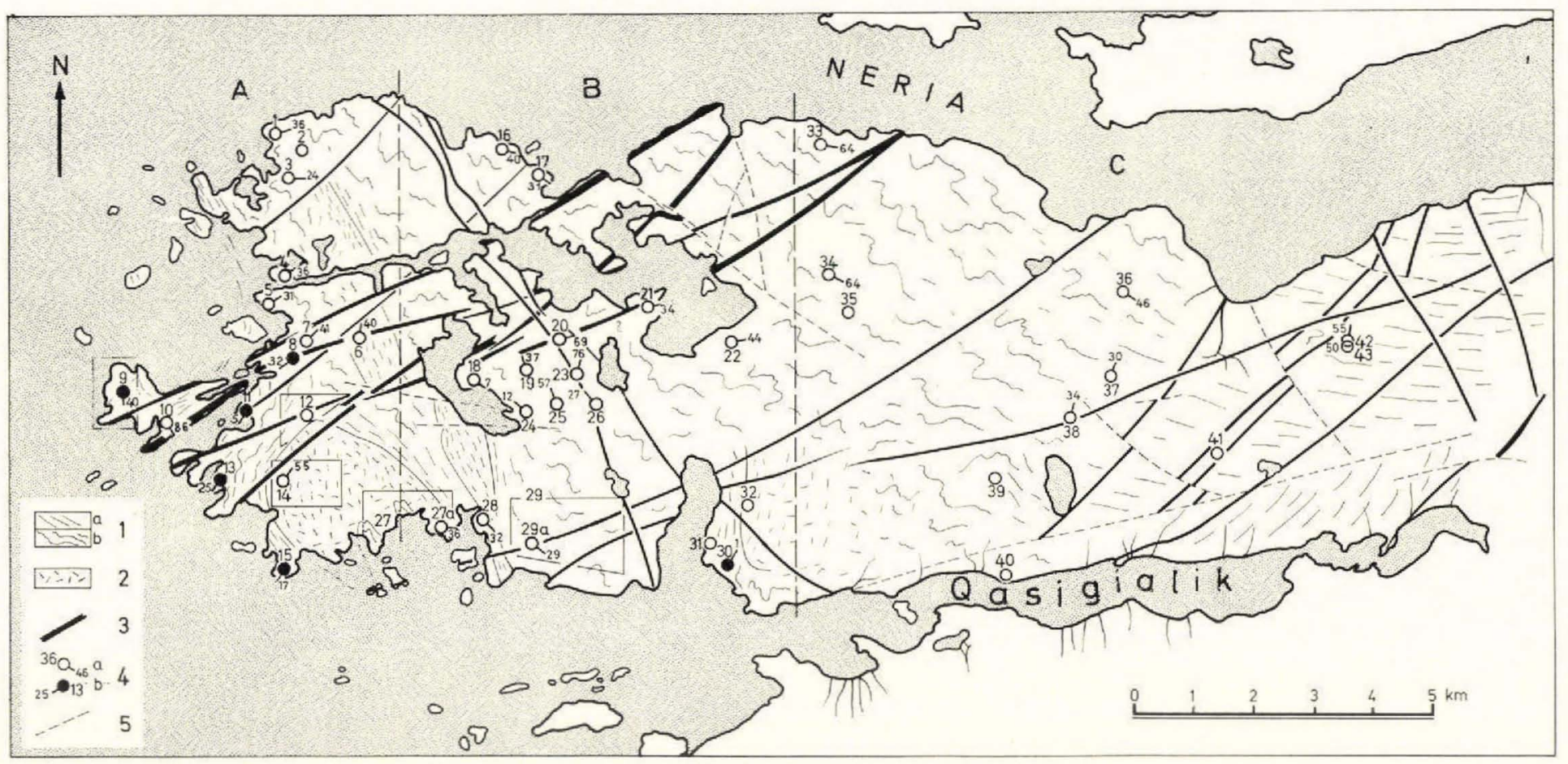

Fig. 1. Geological sketch map of the investigated area.

1. Undifferentiated gneisses, generally strongly migmatitic, 1a with relatively regular structures, $1 \mathrm{~b}$ strongly folded on a minor scale.

2. Leucocratic biotite gneisses.

3. Doleritic dikes.

4. Constructed local fold axes (see text), 4 a assumedly belonging to an older phase of folding ('open folding') than 4b ('large scale folding'). The small size numbers indicate the plunges of the fold axes, the large size numbers are the diagram numbers (see the diagrams at the end of the paper).

5. Faults. 


\section{INTRODUCTION}

D uring the summers of 1963 and 1964, the author carried out geological field work in the Precambrian basement rocks of SW Greenland. The work was carried out under the auspices of G.G.U. (the Geological Survey of Greenland). The investigated area forms a peninsula between Neria and Qasigialik fjords, on the coast of SW Greenland, some $60 \mathrm{~km}$ SE of Frederikshåb.

The main rock types in the area mapped are banded hornblendebiotite gneisses, biotite gneisses, and amphibolites, which generally are strongly migmatized. Of local importance are leucocratic and often very homogeneous biotite gneisses. These rocks are cut in different directions by hosts of basic (mainly doleritic) dykes. Fig. 1 shows a geological sketch map of the area.

During the field work, an attempt was made to determine the large scale fold structures in the gneisses, but due to two causes this proved to be almost impossible. Firstly, there is the scarcity of mappable horizons-the major part of the area consists of migmatites which are very homogeneous on a bigger scale. Secondly, the orientations of the foliation planes in large parts of the area are extremely irregular-even in a single outcrop the rocks are often so strongly folded that it is impossible to indicate a general trend in the foliation. Only in the $W$ part of the area, where several distinct rock units occur, could a few big folds be mapped (see fig. 1).

Although it was impossible (at least for the writer) to get an insight into the structural pattern of the area by mapping any large scale folds, it proved that an analysis of the minor structures gives a fairly good basis for the elucidation of the structural history of the rocks. It was found that the minor (mesoscopic) structures (foliation planes, lineations, minor folds) fit into a more or less regular pattern-in fact one much more regular than expected in these, at first sight structurally chaotic, migmatites (fig. 2).

In the first part of this paper this 'pattern of folding' is described; in the second part an attempt is made to give an interpretation of the facts described. 


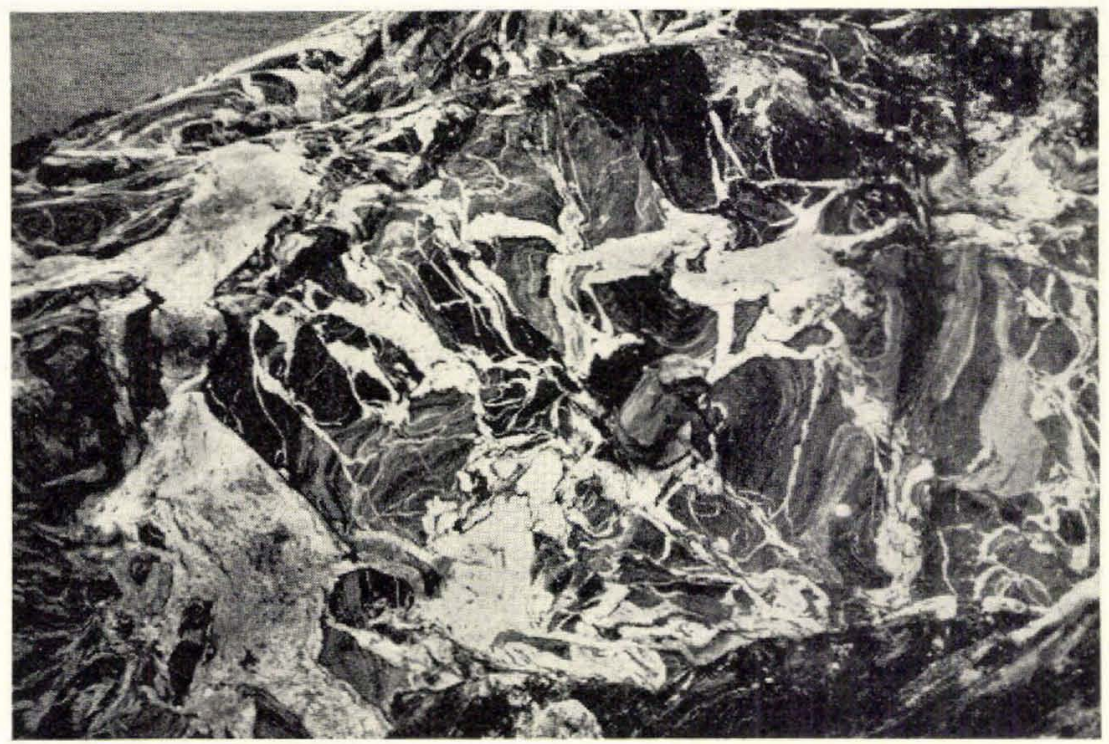

Fig. 2. Agmatitic gneisses and amphibolites, typical for large parts of the area. The rucksack in the centre gives an impression of the size of the outcrop.

\section{Foliation and lineation}

The most common rocks in the area, hornblende-biotite gneisses and amphibolites, are clearly banded, and they exhibit a certain fissility (due to a preferred orientation of hornblende and biotite) in the same direction. They are thus clearly foliated, and generally the strike and dip of the foliation can readily be measured, even in those parts of the area where the gneisses are strongly migmatized. In the biotite gneisses the foliation is generally less distinct, and where the gneisses become more homogeneous, the foliation is sometimes hardly even visible, and often impossible to measure.

In parts of the area the foliation has a rather regular, roughly NW strike and NE dip, but more commonly (especially in the central part of the area), the foliation planes show a very irregular orientation (see fig. 1). Even in those parts of the area, however, where the disposition of the foliation planes is extremely irregular, the structure is locally more regular, and here also the foliation strikes often roughly NW and dips toward NE. Only in the $\mathrm{W}$ part of the area is the general trend of the foliation locally NE.

The hornblende-bearing rocks often show a distinct lineation, due to a parallel alignment of the hornblende crystals. Fig. $3 \mathrm{~A}$ shows the orientation of a number of lineations. As shown by the diagram, the lineations spread very much, but there is a distinet gap in the SW part 
of the diagram. To illustrate this, small circles have been drawn with opening angles of $45^{\circ}$ and $60^{\circ}$ around a SW plunging axis. Some $90 \%$ of the lineations fall outside the $60^{\circ}$ circle. Furthermore it is seen that most of the lineations are concentrated in the $\mathrm{E}$ part of the diagram.

The leucocratic veins in the migmatites, which generally cut discordantly through the foliation of the gneisses, are often clearly foliated and they may show a distinct lineation, due to rodding and folding on a
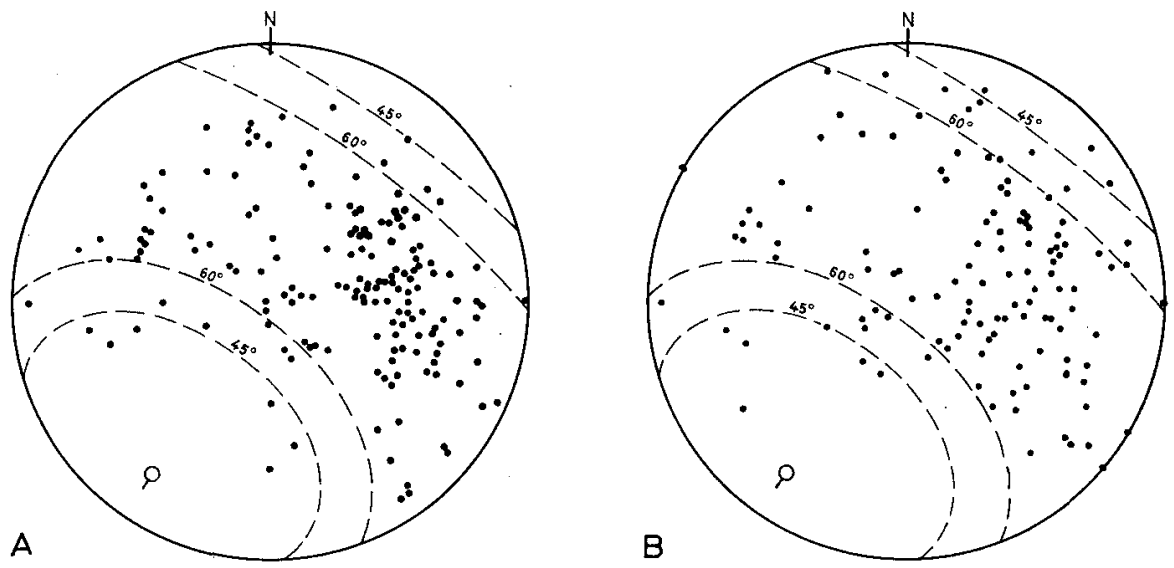

Fig. 3. The orientation of lineation (A) and minor fold axes (B). Equal area projection, lower hemisphere. A) 161 lineations, mainly due to a preferred orientation of hornblende in hornblende-biotite gneisses and amphibolites. B) 124 measured minor fold axes. For further explanation see text.

minor scale. There are, however, also many leucocratic veins which do not show any signs of tectonic influence.

Secondary cleavages (apart from a distinct closely spaced subhorizontal jointing, which is locally developed) are completely lacking.

\section{Minor folds}

Folding on a minor scale is exceedingly common in the major part of the area. Two types of minor folds can be discerned:

a) isoclinal folds (see fig. 4)

b) relatively open folds, mostly with amplitudes of several to several tens of metres.

In the $W$ part of the area two sets of minor folds interfere; here, locally, minor dome structures, with a diameter of several metres, have been developed. An interpretation of these structures is given later. 


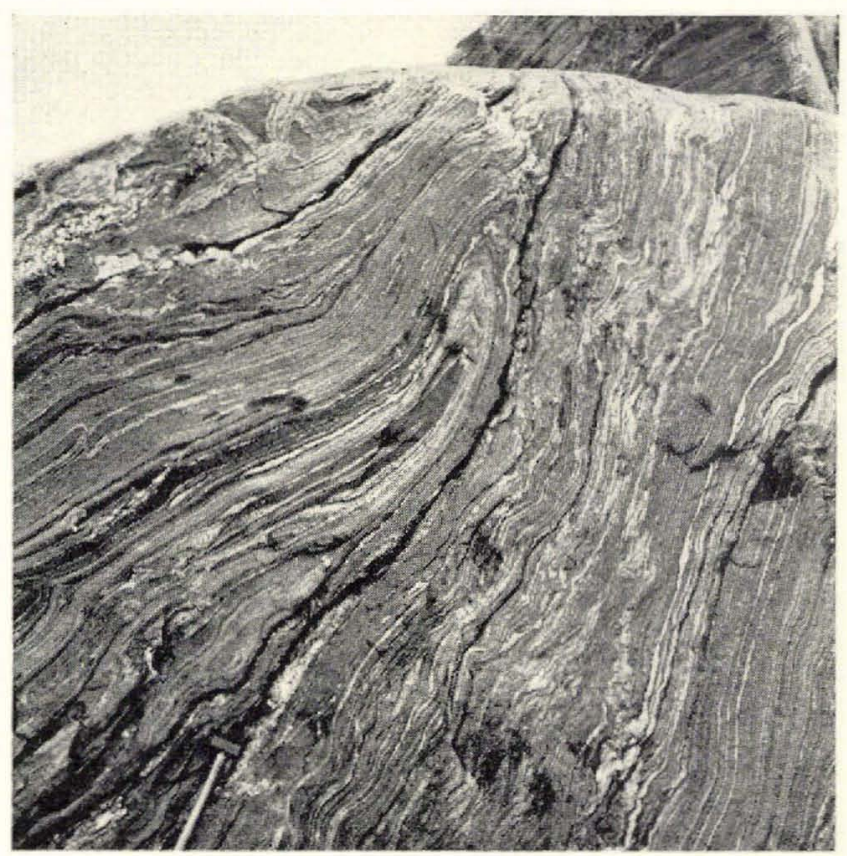

Fig. 4. Isoclinal fold in hornblende-biotite gneiss.

\section{a) Isoclinal folds}

The isoclinal folds have axial planes which lie parallel to the foliation of the gneisses. As stated before, in some parts of the area the foliation has a rather regular NW strike and NE dip. Locally the foliation has even a very regular orientation. In these parts of the area minor isoclinal folds are all the same commonly present. This indicates that the isoclinal folding itself gave rise to a regular orientation of the foliation. Only locally, in the hinge of the folds, the foliation has different orientations.

The fold axes (at least in those cases where the axis of an isoclinal fold could be measured) lie parallel with the lineation in the gneisses.

The isoclinal folds have a 'similar' shape, and thus might be interpreted as shear folds, but no distinct axial plane cleavage is visible.

\section{b) Open folds}

Whereas the isoclinal folds gave rise to a regular orientation of the foliation planes, the open folds really fold the foliation planes. Together with the foliation, the axial planes of the isoclinal folds, which are parallel with the foliation, have been folded. It is not uncommon to find isoclinal folds in different parts of a bigger open fold, always with their axial plane parallel with the foliation at that point. 
The 'open folding' has been intensively active in the major part of the area, especially where the gneisses are strongly migmatized, and it gave rise to a very irregular disposition of the foliation planes in many outcrops. However, even in those parts of the area that were strongly affected by the open folding, localities may be found where, over several tens of metres, the foliation has a relatively regular orientation, and here again the general NW trend of the foliation can often be recognized. In many outcrops, however, such a general trend cannot be distinguished. This does not necessarily mean that it is not present, since sometimes one can see on a distant mountain slope a regular structure in the (migmatized) gneisses, which in the outcrops themselves cannot be confirmed by measurements. The general impression one gets from the open folding is therefore that it disturbs the foliation very strongly on a local scale, but that it does not greatly affect the large scale structure which resulted from the isoclinal folding. This impression could, however, be incorrect, since the large scale fold structures themselves could only exceptionally be studied.

The shape and size of the open folds make it hardly possible to measure the orientation of the axial planes and fold axes. Moreover, the gneisses are generally migmatized to such an extent that it is often impossible to see the folds as a whole; their presence only becomes clear from the irregular disposition of the foliation planes.

To get an insight into the geometry of the open folds, structural diagrams were prepared for a number of localities throughout the area. Strike and dip of some 10-20 foliation planes, in as variable an orientation as possible, as well as a number of lineations and axes of small folds, were measured. The subareas were taken as small as possible; often an area of $100 \times 100 \mathrm{~m}$, or smaller, was big enough to give the desired measurements. Diagrams 1-43 (at the back of the paper) show plots of the measurements in equal area projection, lower hemisphere. Fig. 1 shows the localities where the different sets of measurements were made. Some of the diagrams combine measurements made over bigger areas, see fig. 1.

The results of this investigation may be summarized as follows:

I. In most of the subareas the poles of the foliation planes form roughly a great circle girdle on the diagram, which permits the construction of the local fold axis. Even in strongly veined to agmatitic gneisses (see fig. 2), where the rocks at first sight seem to have lost all regularity in structure, distinct great circle girdles were found (see e.g. diagrams 16 and 33). The photograph of fig. 2 was taken at the very place where the measurements of diagram 16 were made. The foliation in the acid veins, where these are gneissified, fits into the great circle pattern of the gneisses 
(see e.g. diagrams 16, 28, 33, where the foliation of gneissified acid veins is indicated with crosses).

It is seen in many diagrams (e.g. Nos. $1,29,43,37$ ) that the plotted poles spread rather much on either side of a great circle, not only in those cases where the measurements were made in a comparatively large area (No. 29) but also where they come from small subareas (Nos. $43,37)$. In those cases, of course, the construction of the local fold axis may be rather inaccurate. To overcome this difficulty, a method has been developed to calculate the position of the great circle that gives a 'best fit' with the measurements on a diagram (KalsbeEk, 1966), and it has been assumed that the pole of this best fitting great circle is the best approximation of the local fold axis. The necessary calculations are carried out by an electronic computer. The computer not only calculates the orientation of the fold axis which best fits with the measurements, but also the precision with which this orientation can be determined with the measurements available. In the diagrams a $95 \%$ confidence ellipse' (as calculated by the computer) has been drawn around the calculated great circle pole, so that there is approximately $95 \%$ probability that the real fold axis will fall within this ellipse. Further the calculations give a numerical value for the spread in the diagram, namely the standard deviation of the plotted poles from the calculated great circle, measured in degrees.

In a few subareas (e.g. diagrams 12,32 ) the foliations seem to have almost a random distribution in the equal area diagram. The measurements of diagram 12 have been made over a relatively big area, but those of diagram 32 come from an area not bigger than about $25 \times 25 \mathrm{~m}$; the latter measurements were made on amphibolitic inclusions in homogeneous light gneisses. In diagrams 40 and 41 the measurements cluster together, they approach more or less to an irregular 'point' maximum. In such cases (Nos. 12, 32, 40, 41, and others) it does not seem justified to construct a local fold axis, but the computer (having no conscience) calculates its position and confidence ellipse in the normal way. These calculated fold axes and confidence ellipses have also been drawn in the diagrams in which a great circle pattern is not evident; the fold axes have here been indicated with a question mark and the confidence ellipses have been drawn with a broken line. It is clear that such fold axes and confidence ellipses should be used with discretion.

The different calculated fold axes are shown in their proper localities on the map, fig. 1.

II. Generally the calculated fold axis of the open folds is roughly parallel to the lineations and axes of minor folds, measured in the same area. In diagrams 4 and 5, for example, both the constructed fold axes 
and the linear structures plunge NE, in diagrams 16 and 18 both plunge approx. SE, in diagram 10 both are subvertical. The lineation in question generally is the hornblende lineation in the gneisses and amphibolites (which is parallel to the isoclinal fold axes), but lineations (e.g. rodding) and axes of minor folds in the acid veins, where these are folded and gneissified, also plot roughly parallel with the constructed fold axes (see diagrams 16 and 33). The diagrams in figs. 3 and 5 also illustrate the parallelism between the measured lineations and small fold axes (fig. 3, A and B) and the constructed fold axes (fig. 5, D).

It must be pointed out, however, that the parallelism between the measured linear structures and the constructed fold axes is only a rough approximation. In several diagrams (e.g. Nos. 1, 27, 31) the measured lineations and minor axes spread much, and in other ones (e.g. No. 26) the measured linear structures are not at all parallel with the constructed fold axis. The fact that the axes of the open folds are not really parallel with the lineations in the same subarea, is demonstrated by a few minor open folds, with axes roughly parallel to the local constructed fold axis, which clearly refold the hornblende lineation. In those cases the axis of the fold makes a small angle $\left(10-30^{\circ}\right)$ with the lineation.

In a few diagrams from the $W$ part of the area (Nos. 9, 13, 15) it is seen that the measured linear structures are dispersed along small circle girdles. This feature will be discussed later.

III. A comparison between the different local diagrams shows a big variation, from place to place, in the orientation of the constructed fold axes. Plotted together on a new equal area diagram, most of the constructed fold axes fall into new great circle girdles, with $S W$ to WSW plunging axes.

The diagrams of fig. $5 \mathrm{~A}, \mathrm{~B}$ and $\mathrm{C}$, show the orientation of the constructed fold axes in the western, the central, and the eastern parts of the area (as defined in fig. 1). It is seen that, especially in the central and eastern parts of the area, the local fold axes plot, with relatively little spread, along great circle girdles with SW to WSW plunging axes. A few constructed axes do not fall along these new great circle girdles, but instead plot not far from the pole of the new great circles (e.g. 39 in fig. 5 , diagram $\mathrm{C} ; 8$ in diagram A). In diagrams 9,13 and 15, where the measured linear structures fall into small circle girdles, the axes of these small circle girdles plunge towards SW in diagrams 13 and 15, and towards $\mathrm{S}$ in diagram 9-again not far from the pole of the great circle plotted through the different local fold axes. It may thus be stated that the local fold axes fall into two groups: 1) the ones that plot along a great circle, and 2) the ones that plot in the neighbourhood of the pole of this great circle. The latter group, however, shows appreciable spread. In fig. 5, diagram A, 

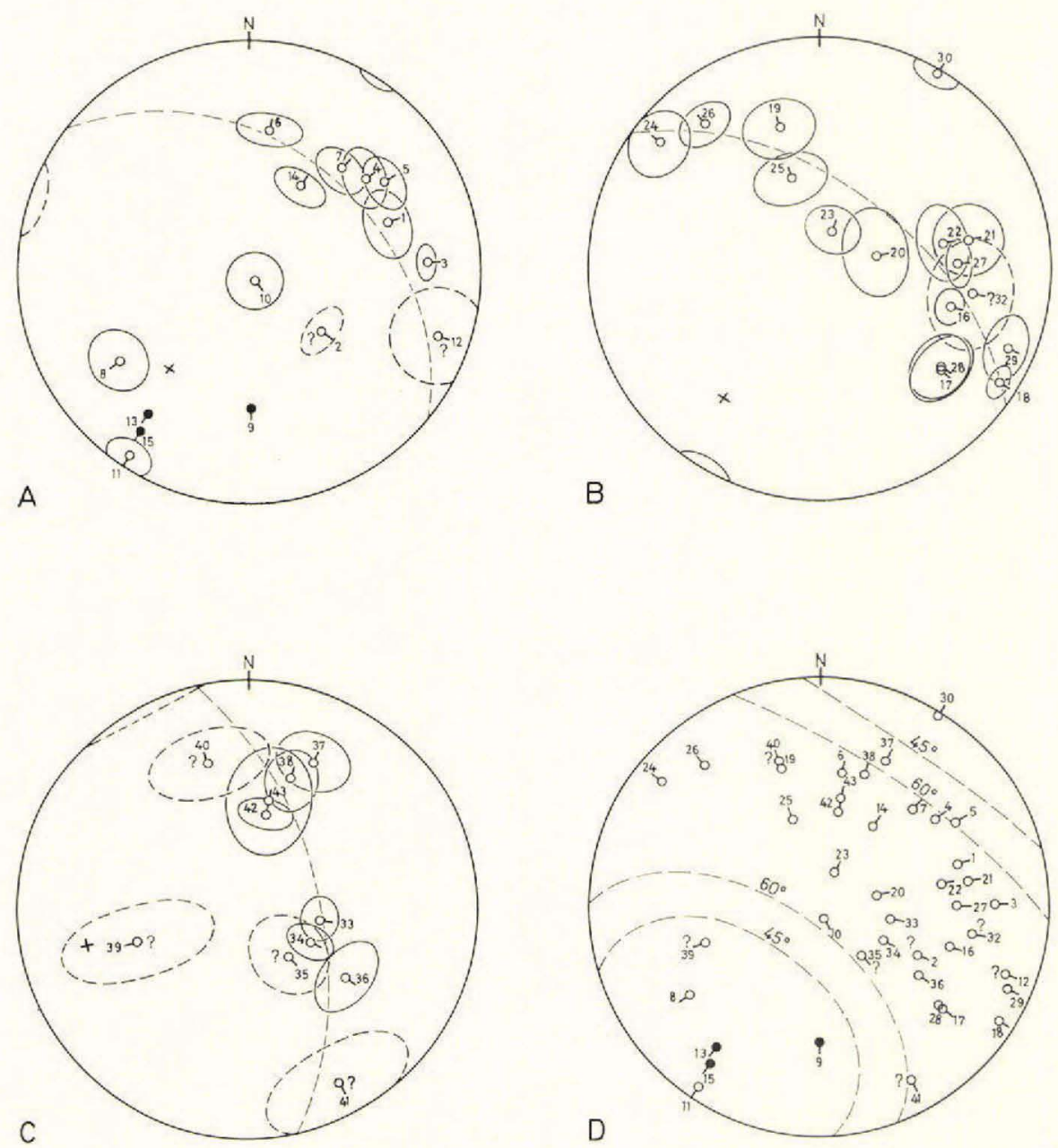

Fig. 5. The orientation of the calculated local fold axes in the western (A) the central (B) and the eastern part (C) of the area. Equal area projection, lower hemisphere. The orientation of all local fold axes is shown in fig. $5 \mathrm{D}$. Compare the local diagrams 1-43. For further explanation see text.

the local fold axes of the second group seem to lie roughly in a great circle girdle with an axis plunging gently towards NW.

Diagram D, fig. 5, shows the orientations of all local fold axes. It is clear that the axes fitting into the great circle patterns of group 1 spread in the same way as the lineations (fig. 3, diagram A) and the small fold axes (fig. 3, diagram B) whereas most of the axes of group 2 fall within that part of the diagram where there is a gap for the lineations and small fold axes.

It may be seen on the map of fig. 1. that the orientation of the constructed fold axes generally does not shift very suddenly in the area. 
Only in the central part of the area (diagrams 18-26) do important changes in the attitude of the constructed fold axes occur within distances of $1 \mathrm{~km}$.

\section{Discussion}

\section{a) The age relationship between isoclinal and open folds}

There are several arguments indicating that the open folds are younger than the isoclinal folds. 1) The open folds clearly affect the axial planes of the isoclinal folds and the lineations that are parallel with the axes of the isoclinal folds. It has been stated that the foliation of the gneisses (parallel with the axial planes of the isoclinal folds) and the lineation (parallel with the axes of the isoclinal folds) are, at least partly, due to the orientation of metamorphic minerals such as biotite and hornblende. This indicates a close relation between isoclinal folding and metamorphism of the rocks. Either the two were contemporaneous, or the hornblende and biotite crystallized mimetically shortly after the folding. The 'open folding', affecting the axial planes and the axes of the isoclinal folds should then be younger than the isoclinal folding and at least part of the metamorphic history. 2) Some of the acid veins in the migmatites, which cut discordantly through the gneisses (and therefore must be younger) are themselves folded. During this folding, a foliation and a lineation were developed in these acid veins, which fit into the open fold pattern. Other acid veins, on the other hand, seem not to be affected by tectonic forces; they are neither foliated nor lineated at all. These relations indicate that, during the migmatization of the rocks, folding took place around axes that conform to those of the open folds.

Whereas, thus, there is ample evidence that the open folds are younger than the isoclinal folds, it seems possible that they originated shortly after them during one semi-continuous phase of folding, metamorphism and migmatization. Firstly there is no reason to assume that the migmatization of the rocks (which of course also took place under metamorphic conditions) and the pre-migmatitic metamorphism were separated by a long time span, and secondly it would explain why the axes of the isoclinal folds and those of the open folds are (at least roughly) parallel-a parallelism that otherwise would be fortuitous.

\section{b) The disposition of the constructed open fold axes}

As has been described, the constructed axes of the open folds do not lie parallel throughout, but they show dispersion in great circle girdles when plotted on an equal area diagram. This seems to indicate that the rocks were not only affected by the isoclinal and the open fold- 
ing, but also by folding around an axis not parallel with the isoclinal and open fold axes. The folds of this type must have a big amplitude in the major part of the area, since generally the constructed open fold axes do not shift very suddenly in attitude. This folding will be referred to as the 'large scale folding'.

Geometrically seen, the disposition of the open fold axes along great circle girdles may be explained in several ways (see TURNER and WeISS, 1963).

I. The 'large scale folding' could be younger than the 'open folding'. The constructed open fold axes would have been parallel originally and would have been dispersed along a great circle girdle during the large scale folding.

(1) In the case that the (younger) large scale folding was a shear folding, the younger fold axis would not necessarily be parallel with the SW plunging axis of the great circle girdle containing the constructed axes of the open folds.

(2) If the (younger) large scale folding was a flexural slip folding, one would expect the constructed open fold axes to be dispersed along small circle girdles and not along great circle girdles, as is the case, unless by coincidence the younger fold axis were perpendicular to the old ones. In that case the younger fold axis would be parallel with the SW plunging axis of the great circle containing the open fold axes.

II. The 'large scale folding' could be older than the 'open folding'. The open fold axes in this case would never have been mutually parallel, but they would have formed in different directions (conforming to a great circle girdle in equal area projection) when the open folds were superimposed on the large scale folds. In this case the axis of the (older) large scale folds would not necessarily coincide with the SW axis of the great circle containing the open fold axes.

III. The absence of any kind of secondary cleavages suggests that in this area one has not (pure) shear folding or flexural slip folding, but that the structures are (at least partly) due to plastic flow. In this case the geometrical abstractions, mentioned above, would not necessarily be valid. The large scale folds and the open folds could then perhaps be formed simultaneously by plastic flow during one phase of folding.

To make a choice from these possibilities on a purely geometrical basis, more data than available (e.g. on the axial planes of the open folds) are needed. As stated before, it is hardly possible to obtain these data. All the same, there is circumstantial evidence that the large scale folding is younger than the open folding, and that the axis of the large scale folds has a SW-NE trend, roughly perpendicular to those of the earlier folding phases. 
1) In the $W$ part of the area, several instances have been found where the lineations (probably connected with the isoclinal folding) have been dispersed along small circle girdles with axes plunging SW to $\mathrm{S}$ (diagrams $9,13,15$ ). This indicates (see e.g. Turner and Weiss, 1963, pp.478-480) that folding, with the geometrical properties of flexural slip folding, folded the earlier lineation around SW plunging axes. It seems rational to assume that the spread of all measured lineations (fig. 3 diagram $A$ ) and the similar spread of the constructed local fold axes (fig. 5 diagram D) are due to the same folding.

2) As has been said before, from a purely geometrical view point, the possibility may not be excluded that the folding on the SW axis preceded the open folding. Nevertheless it seems more probable that the open folding and migmatization took place directly after the isoclinal folding and metamorphism, than that these two were separated by a phase of folding around SW plunging axes.

3) The interpretation that the large scale folding was the youngest phase, and that it had SW-NE axes, fits in with published data from areas more to the south. According to Berthelsen $(1960,1961)$ the youngest folding has $\mathrm{SW}-\mathrm{NE}$ to $\mathrm{W}-\mathrm{E}$ trending axes in the Ivigtut district, whereas an older phase of folding, with NW trending axes was more or less contemporaneous with the migmatization of the rocks.

In the area under discussion, it is impossible to determine the original orientation of the axes of the open (roughly syn-migmatitic) folds, but if they should have been subhorizontal (as often in the Ivigtut district) this would mean that their general trend was NW-SE. In this case there would be a good correlation between the events in both areas.

4) As has been said, it might be postulated that the large scale folds and the open folds do not belong to different folding phases, but formed simultaneously during one phase of folding by plastic flow. It is very questionable, however, whether the regular disposition of the open fold axes along great circle girdles can be explained in this way. Moreover, in the Ivigtut area there is evidence that the folding on NW axes and that on NE-SW axes were clearly separated in time (BERTHELSEN op. cit., Bondesen, 1964).

\section{c) The effects of the large scale folding}

It has been stated that, though the open folding gave rise to a very irregular disposition of the foliation planes, locally the foliation has a regular orientation over several tens to several hundreds of metres, and here, generally roughly NW strikes and relatively steep dips towards NE are found. This 'general trend', which can be recognized in the major part of the area, is roughly perpendicular to the axis of the large scale folding, 
and folding of foliations in this 'general' direction will not occur (cf. Ramsay, 1960).

This feature is clearly exemplified by diagram 15, where the linear structures within the foliation planes are clearly folded, whereas the orientation of the foliation planes themselves is very regular.

In the extreme $\mathrm{W}$ part of the area, where the general trend of the foliation locally turns towards NE (see fig. 1) the younger folding gave rise to folds of the foliation (see diagrams 8 and 11). It is also in this part of the area that minor dome structures have been found; probably these structures originated by the interference of older open folds with folds belonging to the younger large scale folding. Clearly, in the W part of the area, the large scale folding also had its effects on a smaller scale.

In the other parts of the area the influence of the large scale folding is nearly restricted to the dispersion of the local fold axes in great circle girdles. Mesoscopic structures belonging to this phase are rare (exceptions are shown in diagram 30, and, perhaps, 39). This seems to be due to two factors: 1) the large amplitude of the large scale folding and 2) the unfavourable orientation of the general trend of the foliation in relation to the movements which took place during the large scale folding.

The fact that the axes of the folds supposedly belonging to the younger large scale folding are not parallel throughout (see diagrams $8,9,11,13,15,30,39$ (?)) could, of course, be expected, since the orientation of the axis of a fold always depends on the original attitude of the planes which are folded (see e.g. Turner and Weiss 1963, pp. 482486). A spread of these axes along a steep great circle girdle containing the SW plunging axis of the large scale folding (with some phantasy discerned in fig. 5 , diagram $A$, would necessarily be found if the large scale folding had steep axial planes).

\section{d) The use of the calculation of 'best fitting' great circles}

Most of the local great circle diagrams show a considerable spread, and it is therefore impossible to construct the local fold axes accurately in a subjective way. It would be simple to choose, without violating the facts, the local fold axes in such a way that they would fit much better into the new great circle diagrams than they do in fig. 5 . With the help of the computer one gets an objective location of the local fold axes, and the precision of this location, as calculated by the computer, can be indicated with a 'confidence ellipse' drawn around the calculated fold axis. Using these calculated fold axes and confidence ellipses, it has been possible to show, without bias, how the agreement is between the local fold axes and the new great circles in which they are supposed to lie (fig. 5). 
It has been said before that in a number of diagrams the measurements spread so much that it does not seem justified to construct a local fold axis. With the help of the computer, the best fitting great circles have also been calculated for these diagrams. In these cases, of course, the confidence ellipses are large. One may say (and the writer agrees) that it is doubtful whether such a 'fold axis' has any geological meaning. It proves, however, that all these doubtful fold axes fit well into the general picture. Most of them fall into the great circle patterns of fig. 5 (Nos. 12, 32, 35, 40, 41), the two remaining ones (Nos 2 and 39) fall near a subvertical great circle trough the SW plunging axis of the large scale folds. These facts indicate that perhaps the location of a fold axis in badly defined great circle diagrams has more sense than one would suppose at first sight.

\section{Summary}

The observations and measurements on minor structures in the area may be fitted into the following scheme:

1. Isoclinal folding. Axial planes parallel with the foliation of the gneisses, fold axes parallel with the lineation in the gneisses. Metamorphism during or shortly after the isoclinal folding.

2. 'Open folding'. Axial planes cannot be measured, and are not expressed as a secondary cleavage. Fold axes can be constructed from local structural diagrams; they are generally roughly parallel with the axes of the isoclinal folds. The open folding was roughly contemporaneous with the migmatization of the gneisses. Possibly isoclinal folding, metamorphism, open folding and migmatization took place during one complex orogenic phase, without long periods of rest in between.

3. 'Large scale folding'. Axial planes steep(?). Fold axes trend SW-NE and plunge gently towards SW. In the E part of the area they turn more towards $W$. Since the fold axes are roughly perpendicular to the general trend of the foliation, this general direction is hardly affected by the large scale folding.

It is possible that at least some of the folds are due to plastic flow. In geometric properties the isoclinal folding seems to approach shear folding. The open and large scale folding seem more to approach flexural slip folding.

The correctness of this interpretation cannot completely be proven along geometrical lines, but it seems, on general geological grounds, the most acceptable explanation of the observed data. Moreover, it fits in with the evidence from areas more to the south. 


\section{REFERENCES}

Berthelsen, A. (1960): An example of a structural approach to the migmatite problem. Rep. Intern. Geol. Congr. XXI. Session, Norden, Part XIV, pp. 149-157.

- (1961): On the chronology of the Precambrian of western Greenland. In RAAsch, G. O. (edit) Geology of the Arctic, vol. 1, pp. 329-338, University of Toronto Press.

Bondesen, E. (1964): An intrusion breccia with associated ultrabasics from Sermersût, South-West Greenland. Medd. Grønland, Bd. 169, nr. 7, pp. 1-36.

KALsBék, F. (1966): Quantitative and semiquantitative treatment of great circle patterns. Neues Jahrb. Miner. Abh. 105, pp. 18-40.

RAmSAY, J. G. (1960): The deformation of early linear structures in areas of repeated folding. J. Geol., vol. 68, pp. 75-93.

Turner, F. J. and L. E. Weiss (1963): Structural analysis of metamorphic tectonites. McGraw-Hill, New York. 


\section{Diagrams 1-43}

Structural diagrams for a number of subareas. Dots: normals to foliation planes of gneisses; crosses: normals to the foliation in acid veins. The broken great circles are great circles of 'best fit' as calculated by the computer. The pole to this great circle (the fold axis) is indicated with a cross, the ellipses drawn around the fold axes $(95 \%$ confidence ellipses) indicate the area within which the real fold axis will very probably lie. For diagrams which do not show clear great circle patterns, the calculated fold axis is shown with a question mark; the $95 \%$ confidence ellipse is broken.

Dots with a tail: lineation in gneisses. Dots with a cross: lineation in acid veins. Circles with a tail: minor fold axes in gneisses. Circles with a cross: minor fold axes in acid veins.

$\mathrm{N}$ : the number of measurements of foliation planes on which the calculation of the best fitting great circle is based.

$\mathrm{S}$ : the 'spread factor' of the diagram, a numerical value for the spread of the poles, calculated by the computer.

All diagrams are equal area projections, lower hemisphere. The localities where the measurements were made are indicated in fig. 1.

A discussion of the diagrams is given in the text. 


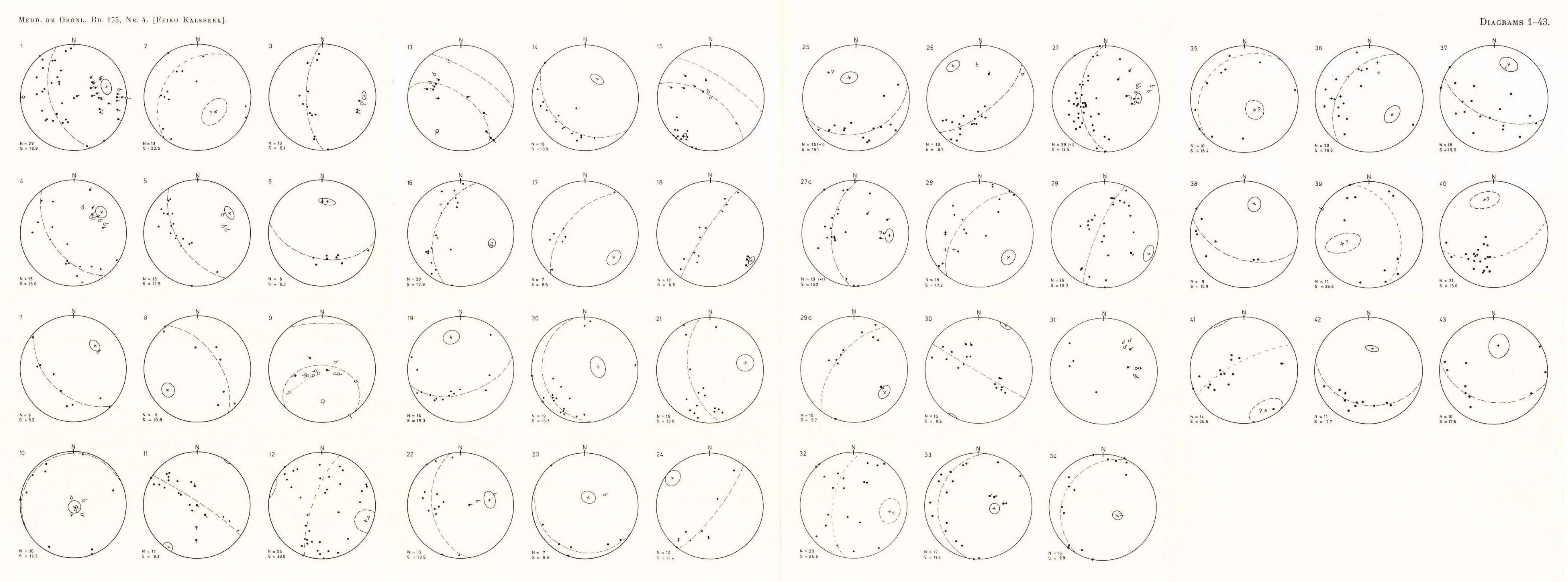

